(RESEARCH ARTICLE)

\title{
Nutritional status of children from 6-59 months received in the dietary service of the Regional Hospital of Daloa (Côte d'Ivoire)
}

\author{
Beugré Grah Avit Maxwell *, Niaba Koffi Pierre Valery, Combo Agnan Marie-Michel, Yao N'zué Binjamin and \\ Gnakri Dago
}

Department of Biochemistry-Microbiology, Laboratory of Agrovalorisation, University Jean Lorougnon Guédé, Côte d'Ivoire.

Publication history: Received on 20 April 2019; revised on 10 June 2019; accepted on 12 June 2019

Article DOI: https://doi.org/10.30574/wjarr.2019.2.2.0030

\begin{abstract}
Côte d'Ivoire's membership in Scaling Up Nutrition (SUN) is a momentum in a collective effort to improve the nutrition and nutritional status of the population. This nutritional status study is part of this process and aims to assess the nutritional status of children aged 6 to 59 months in the dietary department of the Regional Hospital of Daloa. To do this an evaluation of the nutritional status is carried out. For this purpose, the anthropometric measurements of the children were carried out. The survey found that acute malnutrition affects $44.34 \%$ of children aged 6 to 59 months receiving dietary services from the Regional Hospital of Daloa and 31.13\% suffer from severe forms. In fact, children aged 6 to 59 months suffered from stunting, of which $38.68 \%$ were severe and $56.60 \%$ of children aged 6 to 59 months were underweight.
\end{abstract}

Keywords: Nutrition; Nutritional status; Anthropometric measurements

\section{Introduction}

According to the UN Food and Agriculture Organization (FAO), malnutrition affects more than one billion people worldwide, $90 \%$ of them in developing countries. It mainly affects vulnerable groups such as children under 5 , pregnant women and women who are breastfeeding [1]. Thus, it contributes to $33 \%$ of infant mortality, an estimated loss of life of 128,354 deaths of children under five each year [2]. In Côte d'Ivoire, acute malnutrition affected $8 \%$ of children under five years of age with $2 \%$ suffering from severe forms, $15 \%$ underweight and $30 \%$ suffering from stunted growth, of which $12 \%$ was severe [3]. The Ivorian diet is generally not very diversified, mainly based on tubers, roots and cereals which contribute more than $65 \%$ to energy intake [4].

In 2012, only $7 \%$ of children and infants received a diet of minimal quality in terms of both diversity and frequency of meals [5]. In addition, the main causes of malnutrition are related to a protein-energy deficit and a deficiency of certain key micronutrients, namely calcium, iron and zinc [6]. Côte d'Ivoire is aware of the double burden of undernourishment, which is marked by under-nutrition (stunting, acute malnutrition, underweight, and micronutrient deficiencies), the emergence of over-nutrition (overweight and obesity) and diseases, chronic noncommunicable diseases related to nutrition [7].

In the city of Daloa (Upper Sassandra Region, Côte d'Ivoire), one of the densest in the country, the nutritional status of children from 6 to 59 months remains to be determined. The present study aims to assess the nutritional status of children aged 6 to 59 months in the dietary department of the Regional Hospital of Daloa.

\footnotetext{
${ }^{*}$ Corresponding author

E-mail address: maxwellfrb@yahoo.fr
} 


\section{Material and methods}

\subsection{Study framework}

This study was conducted in the dietary department of the Regional Hospital of Daloa. The dietary service of the Regional Hospital of Daloa is an administrative establishment. Daloa is a city in west-central Côte d'Ivoire, West Africa.

\subsection{Material}

The material used consists of a SECA brand weight scale weighing scale with maximum capacity of $150 \mathrm{~kg}$ and an accuracy of $100 \mathrm{~g}$; horizontal height of two meters, which was used to measure the size to the millimeter and a MUAC for the brachial perimeter; an individual survey sheet used to collect the data; a computer used for recording, statistical analysis of data obtained using specific software and final editing.

\subsection{Methods}

\subsubsection{Preparation of the survey}

Anthropometric measurements and the food consumption survey were conducted on a sample of 106 children. The survey questionnaire consisted of socioeconomic, demographic and dietary characteristics of the study population. Sex, relationship with the child, type of dwelling, level of education, nutrition education, prenatal consultation, age of dietary diversification, supplementary food, food budget and household size were the parameters selected for the parents of the children. The socio-demographic characteristics of the children were gender, age in months, birth weight, height, weight, and the brachial perimeter.

\section{Results and discussion}

\subsection{Characteristics of the study population}

The surveyed child population was $48.4 \%$ boys versus $51.6 \%$ girls (Figure 1 ). During the consultations, $80.6 \%$ of the children were accompanied by their mother, $6.5 \%$ by their father and $12.9 \%$ by their grandparents (Figure 2 ). A proportion of $74.2 \%$ of the mothers present had optimal vaccine status and regular CPN compared with $25.8 \%$ of mothers who had not followed CPN before delivery (Figure 4). Parents' education was low, as $61.3 \%$ of them had no education. In contrast, $29 \%$ had primary education and $9.7 \%$ secondary education (Figure 3 ).

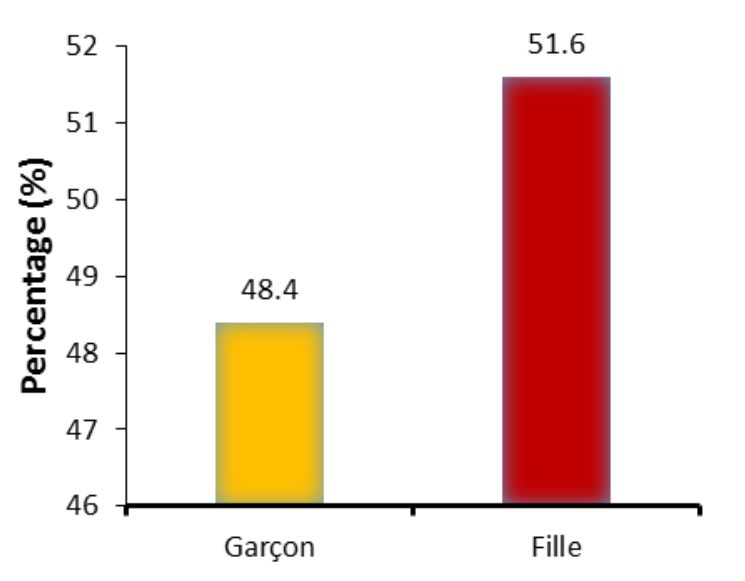

Figure 1 Distribution of children by sex 


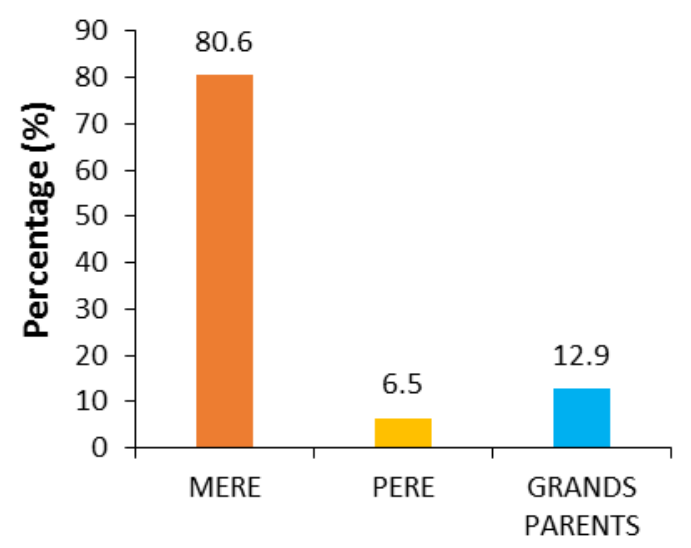

Figure 2 Parents accompanying the child during the consultation

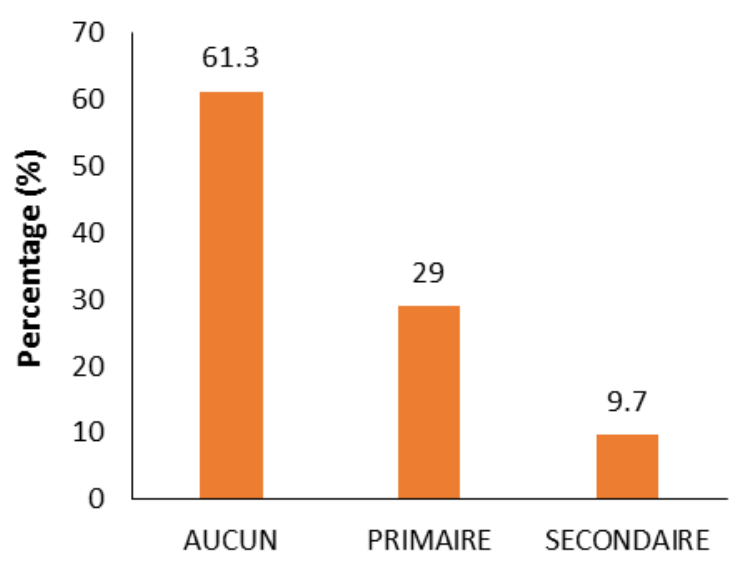

Figure 3 Parents' level of education

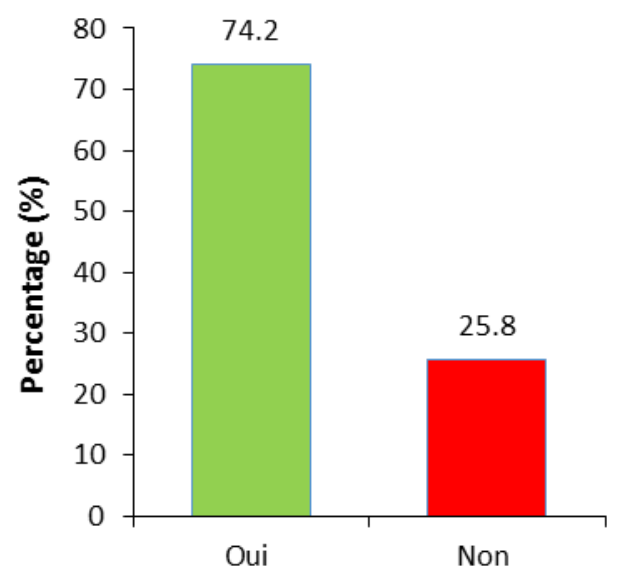

Figure 4 Maternal prenatal consultations

\subsection{Parents' knowledge of good nutritional practice}

The study showed that $80.6 \%$ of parents had no knowledge of nutrition education compared to $19.4 \%$ who had notions of infant nutrition (Figure 5). Regarding the type of breastfeeding, 38.7\% of mothers practiced exclusive breastfeeding and $45.2 \%$ mixed breastfeeding, compared with $16.1 \%$ who breastfed for replacement (Figure 6). The age of dietary diversification for children was $12.9 \%$ at 6 months compared with $54.8 \%$ for children under 6 months and $32.3 \%$ for children over 6 months of age (Figure 7). Children's supplemental food consisted mainly of $64.5 \%$ boiled, $6.5 \%$ cow's milk and $29 \%$ other products (Figure 8 ). 


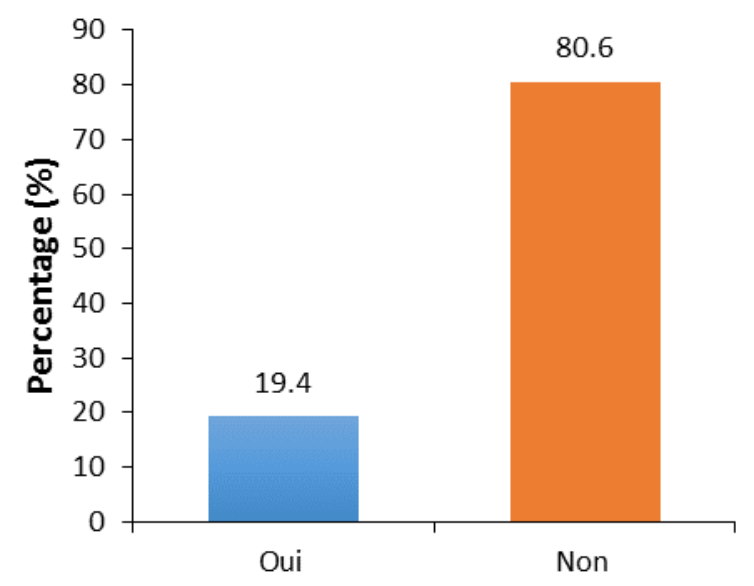

Figure 5 Parents' knowledge of nutrition

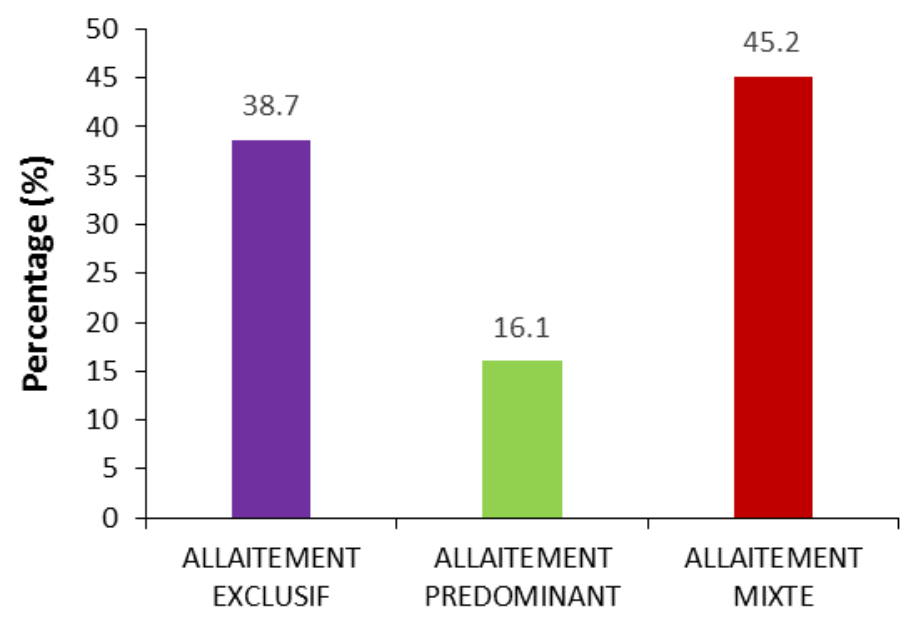

Figure 6 Type of breastfeeding of children

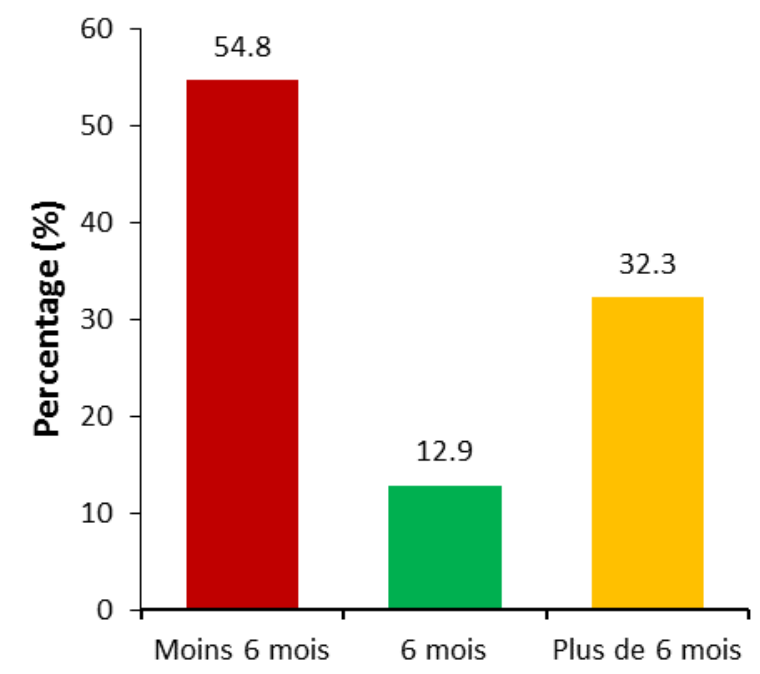

Figure 7 Age of beginning of diversification 


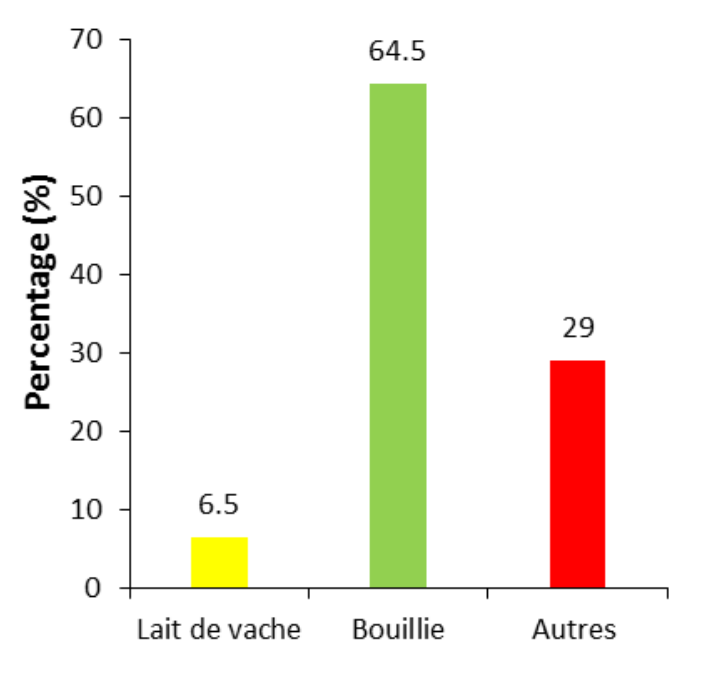

Figure 8 Complementary foods used

\subsection{Demographic and socio-economic characteristics of children}

The study showed that $67.7 \%$ of the children surveyed had a birth weight of more than $2500 \mathrm{~g}$ and $6.5 \%$ a birth weight of $2500 \mathrm{~g}$. In contrast, $25.8 \%$ of the children had a low birth weight of less than $2500 \mathrm{~g}$ (Figure 9). For the type of dwelling, $51.6 \%$ of the families lived in simple hard houses compared to $35.5 \%$ in clay and $12.9 \%$ lived in houses made of wood (Figure 10). The daily food budget was less than FCFA 500 for $45.2 \%$ of households and between CFAF 500 to 1000 for $38.7 \%$ of households against $16.1 \%$ which had more than 1000 FCFA (Figure 11). The number of people in households was estimated at $19.4 \%$ between 5 to 10 people and $22.6 \%$ to less than 5 people against $58 \%$ more than 10 people in the household (Figure 12).

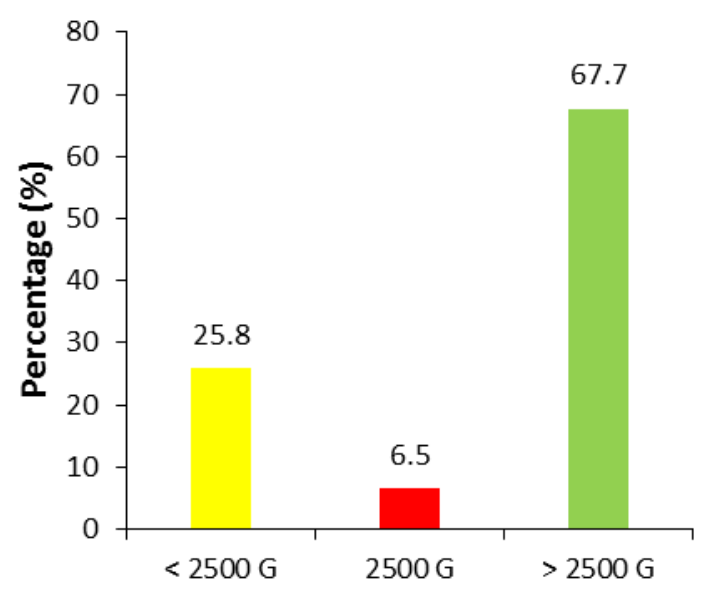

Figure 9 Birth weight of children 


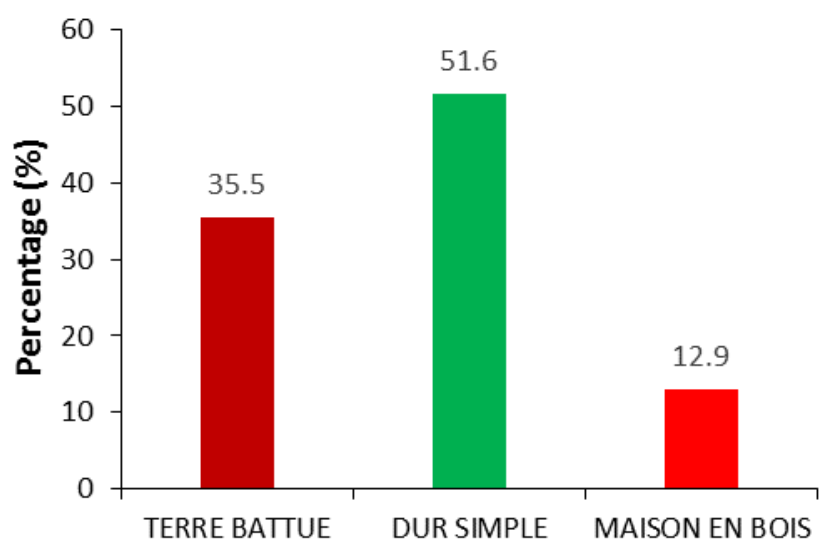

Figure 10 Type of family home

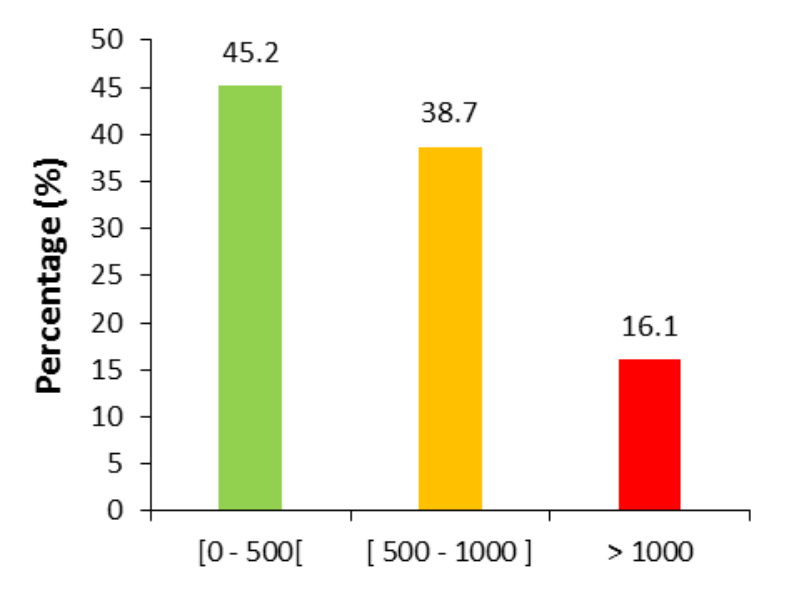

Figure 11 Daily household food budget

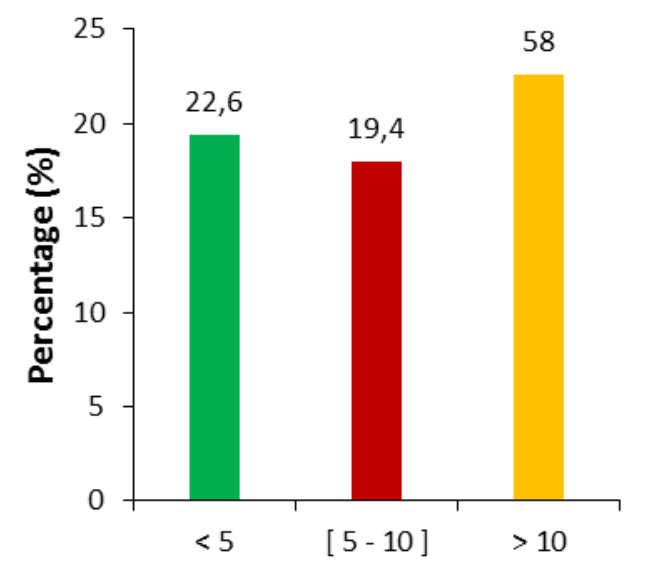

Figure 12 Household size

\subsection{Assessment of the nutritional status of the children surveyed}

The survey revealed that acute malnutrition affects $44.34 \%$ of children aged 6 to 59 months receiving dietary services from Regional Hospital of Daloa and 31.13\% suffering from severe forms. Indeed, children aged 6 to 59 months suffered from stunting, of which $38.68 \%$ were severe and $56.60 \%$ of children aged 6-59 months were underweight (Table I). 
Table 1 Distribution of children by nutritional status

\begin{tabular}{lcccccc}
\hline & \multicolumn{2}{c}{ Acute malnutrition } & \multicolumn{2}{c}{ Chronic malnutrition } & \multicolumn{2}{c}{ Underweight } \\
\cline { 2 - 7 } & Effective & $\mathbf{\%}$ & Effective & $\mathbf{\%}$ & Effective & \% \\
\cline { 2 - 7 } Normal state & 59 & 55,66 & 38 & 35,85 & 46 & 43,40 \\
Moderate form & 14 & 13,21 & 27 & 25,47 & 19 & 17,92 \\
Severe form & 33 & 31,13 & 41 & 38,68 & 41 & 38,68 \\
\hline
\end{tabular}

\section{Discussion}

\subsection{Characteristics of the study population}

The present study was conducted to investigate the determinants of malnutrition and to contribute to the improvement of the nutritional quality of complementary foods in order to combat malnutrition in Daloa. It involved a representative sample of 106 children aged 6 to 59 months who came for consultation to the dietary department of the Regional Hospital of Daloa. During the survey, the number of boys was slightly lower than that of girls with a sex ratio of 0.94 . On the other hand, a study conducted in 2016 on the nutritional situation of the country indicated that the number of boys was higher than that of girls with a sex ratio higher than 1 [8]. Regarding the educational level of parents of children, among educated mothers, only $29.0 \%$ had a primary level and $9.7 \%$ had a secondary level. The literacy rate for women remains low. According to the 2011-12 EDS-MICS, 53\% of women of childbearing age had no level of education, which strongly influences women's ability to develop leadership to improve the nutritional status of their household [9]. For the prenatal consultations, the survey found that mothers had updated immunization status, which is in agreement with [10] who found that in $70 \%$ of cases, mothers have their status vaccinal update.

\subsection{Parents' knowledge of good nutritional practice}

Regarding the level of nutritional education, the majority of parents (80.6\%) had no knowledge of infant nutrition. In line with the [11] survey, which states that $53 \%$ of women of childbearing age have no level of nutritional education, this state of affairs could influence women's ability to the management of nutritional situations in her household and lead mothers to abandon exclusive breastfeeding in favor of replacement and mixed breastfeeding. The practice of early initiation of breastfeeding is even rarer in some areas of Côte d'Ivoire, where the Central West (55\%) is moving higher rates [12]. The survey found that porridge was the most commonly consumed food (64.5\%) by children as a diversification food after 6 months. However, several foods were introduced into the children's diet before the age of 6 months. These foods include water, porridge and fruit juices. This has also been pointed out in the works of [13]. In Côte d'Ivoire, data from [14] showed that solid, semi-solid or liquid foods are appropriately introduced in $64 \%$ of children aged 6 to 8 months.

\subsection{Demographic and socio-economic characteristics of children}

The study showed that a quarter of the children had birth weight of less than 2500 g. Many children continue to be born with low weight. Indeed, it was estimated in 2012, at $14 \%$ the proportion of children born with a weight of less than $2500 \mathrm{~g}$, as confirmed by [5]. The majority of the families surveyed had a daily food budget of less than 1000 FCFA. These results are different from those of [15] indicating that, more than half of the households had a daily food budget of between 1000 and 2000 FCFA asserted in a study on the nutritional status of children from 6 to 59 months. The number of people in the household was prioritized between 5 to 10. A number of people per household over ten and the father's self-employment were identified as risk factors for malnutrition [16]. The relationship between malnutrition and household size stems from the finding that malnutrition situations arise from the difficulties of large families in ensuring their food security [17].

\subsection{Assessment of the nutritional status of the children surveyed}

During the survey, the prevalence of acute malnutrition (44.34\%) is above $10 \%$ of the acceptable threshold. What constitutes a rather worrying nutritional situation in Daloa according to the WHO standards which indicates that a P / $\mathrm{T}$ index between 5 and $10 \%$ is a severe situation and at $10 \%$ the situation is considered as serious that can lead to on a nutritional emergency. Indeed, stunting (64.15\%) is the most common form in the Daloa region, in children aged 6 to 59 months. The data from the 2011 nutrition survey, based on the SMART methodology, are consistent with these 
results for a national prevalence of stunting of $27 \%$ with an upper limit of $29 \%$ taking into account sampling fluctuations. The prevalence of stunting is considered to be serious at the national level compared to an acceptability rate of $20 \%$ [14]. The prevalence of underweight $(56,60 \%)$ was greater than $10 \%$, the acceptable threshold. She is considered serious in this region. Malnutrition also has consequences for child mortality. Despite a downward trend in all regions, malnutrition rates remain near the critical threshold of $40 \%$ in the Far North (Northeast, North, and Northwest) and the West Coast Côte d'Ivoire Coast [18].

\section{Conclusion}

The present study was conducted to make the state of child malnutrition in Daloa. The goal is to assess the nutritional status of children aged 6 to 59 months in the Daloa region and the nutritional quality of infant flours offered to mothers. At the end of this study, it is important to remember that Daloa is facing a problem of malnutrition with prevalences of malnutrition in unacceptable thresholds and all forms. The survey found that acute malnutrition affects $44.34 \%$ of children aged 6 to 59 months receiving dietary services from the Regional Hospital of Daloa and 31.13\% suffer from severe forms. In fact, children aged 6 to 59 months suffered from stunting, of which $38.68 \%$ were severe and $56.60 \%$ of children aged 6 to 59 months were underweight. This study should open with a survey to assess the prevalence of micronutrient deficiencies in the Daloa region to better understand the problem of malnutrition.

\section{Compliance with ethical standards}

\section{Acknowledgments}

Authors are grateful to the President of the University Jean Lorougnon Guedé of Daloa, Professor Tidou Abiba Sanogo, wife Koné for her technical assistance.

\section{Disclosure of conflict of interest}

The authors, Beugré Grah Avit Maxwell, Niaba Koffi Pierre Valery, Combo Agnan Marie-Michel, Yao N’zué Binjamin, Gnakri Dago, declare that there is no conflict of interest that exists.

\section{References}

[1] FAO (2009). The state of food and agriculture, Rome, 202.

[2] Black RE, Victora CG, Walker SP, Bhutta ZA, Christian P, De Onis M, Ezzati M, Grantham-McGregor S, Katz J, Martorell R and Uauy R. (2013). Maternal and child undernutrition and overweight in low-income and middleincome countries. The lancet, 382(9890), 427-451.

[3] INS and ICF. (2012). Demographic and Health Survey and Multiple Indicators. Pathways of development Multidimensional review of Côte d'Ivoire. Calverton, Maryland, USA: National Institute of Statistics and ICF International. 216.

[4] Camara F, Brou K, Assemand EF, Tano K and Dago G. (2009). Quantification of the energy, iron intake and the promoter and inhibitors absorption in rural and urban Côte d'Ivoire. Eur J Sci Res, 35(1), 130-141.

[5] PND. (2012). Theme 1: Executive summary. Ivory Coast: 29 August 2012. 59 p.

[6] Soro S, Konan G, Elleingand E, N'guessan D and Koffi E. (2013). Formulation of infant foods based on yam flour enriched with soy. Laboratory of Biochemistry and Food Sciences; Biosciences, University of Cocody, Abidjan 22 Bp 582 Abidjan 22, Ivory Coast.

[7] RCI (2015). Analysis of the nutritional situation in Côte d'Ivoire. 20-p. www.nutrition.gouv.ci/fichier/doc/Analyse_situationnelle_15_08_1.

[8] Viviane JZT, Kouame GMB, Koffi GK and Brou AK. (2011). Study of the nutritional value of cassava-based infant flours and soybeans for children of weaning age. Laboratory of Nutrition and Pharmacology, UFR-Biosciences, University of Cocody, Ivory Coast, 748 - 758.

[9] Doublier JL. (2009). Reminder on starches and wheat flour. INRA Nantes. Research Unit Biopolymers, Interactions, Assemblies.

[10] Nelson RM. (1987). Introduction to the 1986 Atwater Lecture. The American Journal of Clinical Nutrition, 45(5), 896-897. 
[11] Kinsella JE. (1976). Functional properties of proteins in foods: a survey. CRC Critical Review in Food Science and Nutrition, 7, 219-280.

[12] WHO / FAO / UNU (1986). Joint FAO / WHO / UNU Expert Consultation on Energy Requirements and Protein Requirements. Food and Agriculture Organization of the United Nations, World Health Organization and United Nations University.

[13] Okezie OB and Bello AB. (1988). Physicochemical and functional properties of winged bean flour and isolate compared with soy isolate. Journal of Food Science, 53(2), 450-454.

[14] François L, Lionel S, Jean MS and Ali C. (2007). Use of misola meal in infant and young child feeding. MISOLA Association 12 rue des Soupirants 62100 CALAIS, 35.

[15] Sefa-Dedeh SKY and Afoakwa E0. (2001). Influence of fermentation and cowpea steaming on some quality characteristics of maize-cowpea blends. African Journal of Science Technology, 2, 71-80.

[16] Redhead J. (1990). Use of tropical foods: tropical oilseeds. FAO, Rome. Food and Nutrition Studies, 47-55.

[17] Mouquet-Rivier. (2006). Complementary feeding of young children in Burkina Faso. Open day of the "CIRD", IRD center of Ouagadougou. Power point presentation. 1-59.

[18] De Vries JW, Prosky L, Li B and Cho S. (1999). À historical perspective on defining dietary fiber. American Association of Cereal Chemists, 44 (5), 367-368.

\section{How to cite this article}

Beugré GAM, Niaba KPV, Combo AMM, Yao NB and Gnakri D. (2019). Nutritional status of children from 6-59 months received in the dietary service of the Regional Hospital of Daloa (Côte d'Ivoire). World Journal of Advanced Research and Reviews, 2(2), 01-09. 